Supplement of The Cryosphere, 14, 1727-1746, 2020

https://doi.org/10.5194/tc-14-1727-2020-supplement

(c) Author(s) 2020. This work is distributed under

the Creative Commons Attribution 4.0 License.

(c) (1)

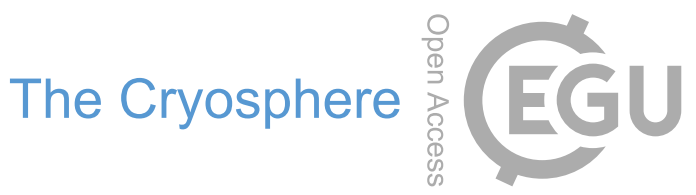

Supplement of

\title{
Evaluation of Arctic sea ice drift and its dependency on near-surface wind and sea ice conditions in the coupled regional climate model HIRHAM-NAOSIM
}

Xiaoyong Yu et al.

Correspondence to: Xiaoyong Yu (xiaoyong.yu@awi.de)

The copyright of individual parts of the supplement might differ from the CC BY 4.0 License. 
model

(a)

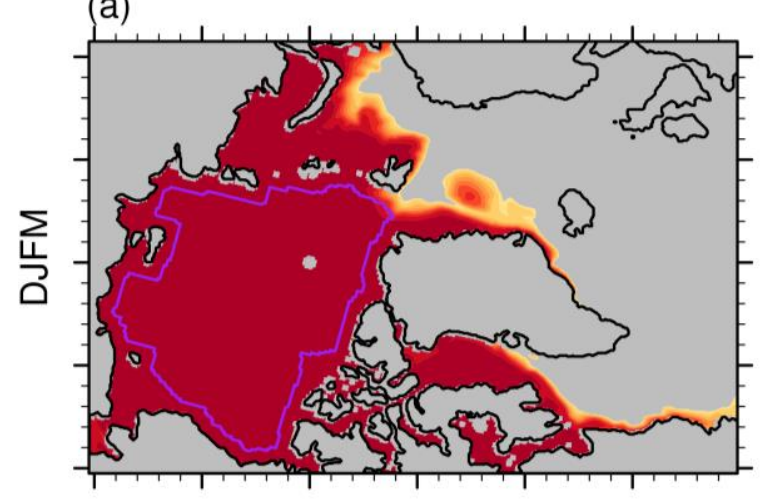

(c)

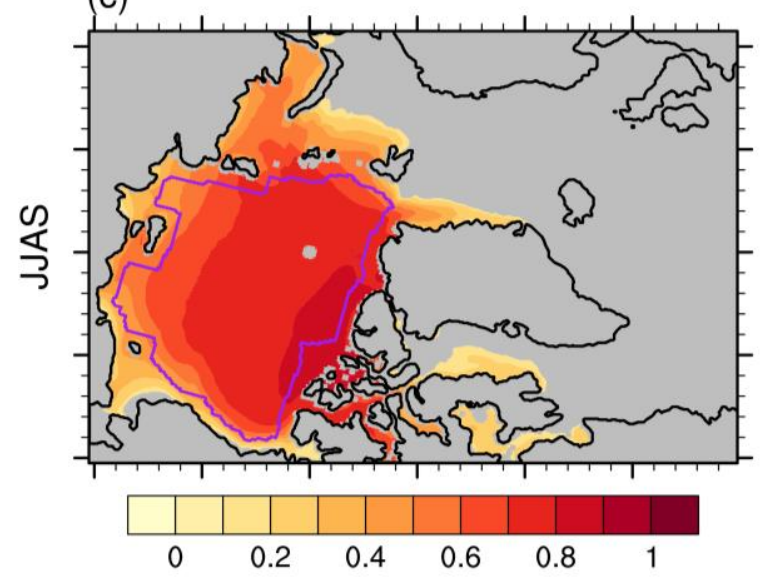

model - NSIDC bootstrap

(b)

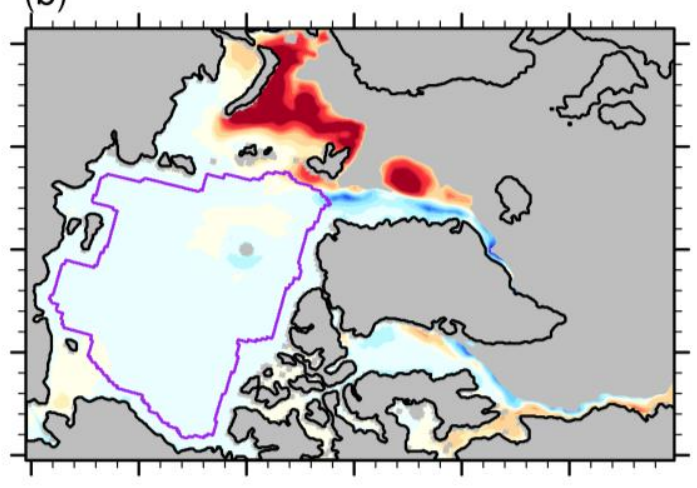

(d)

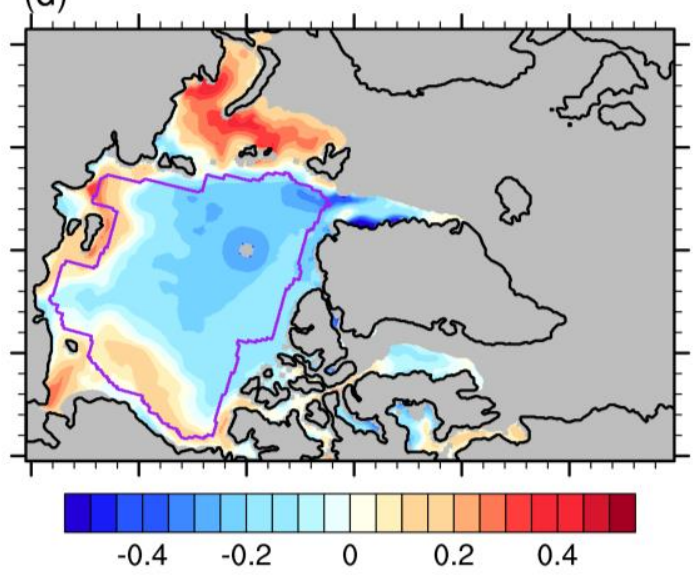

Figure S1: Mean spatial pattern of sea-ice concentration in the model (ensemble mean of HIRHAM-NAOSIM 2.0) for 2003-2014 (a) winter

(DJFM) and (c) summer (JJAS). (b) and (d) are the model differences to the observation ("Model - NSIDC bootstrap") for winter and summer respectively. The purple line in each panel indicates the study domain used for the basin-wide analysis. 

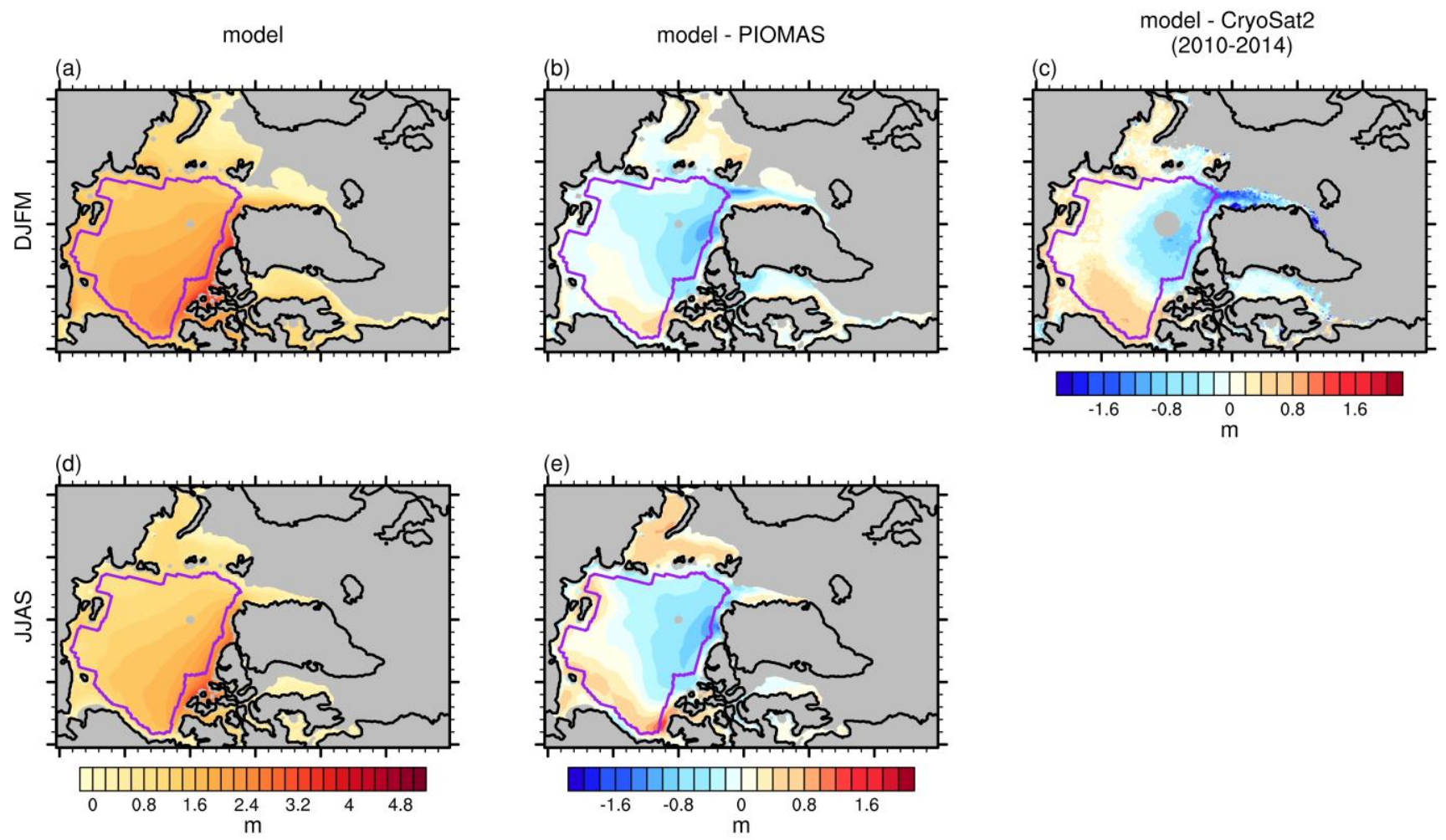

Figure S2: Mean spatial pattern of sea-ice thickness [m] in the model (ensemble mean of HIRHAM-NAOSIM 2.0) for 2003-2014 (a) winter

(DJFM) and (d) summer (JJAS). (b) and (e) are the model differences to the PIOMAS ("Model - PIOMAS") for 2003-2014 winter and summer respectively. (c) are the model differences to the CryoSat-2 sea-ice thickness for 2010-2014 winter. The CryoSat-2 monthly mean gridded sea-ice thickness data are download from ftp.awi.de/sea_ice/product/cryosat2/v2p2/nh/13c_grid/monthly. The purple line in each panel indicates the study domain used for the basin-wide analysis. 
model

(a)

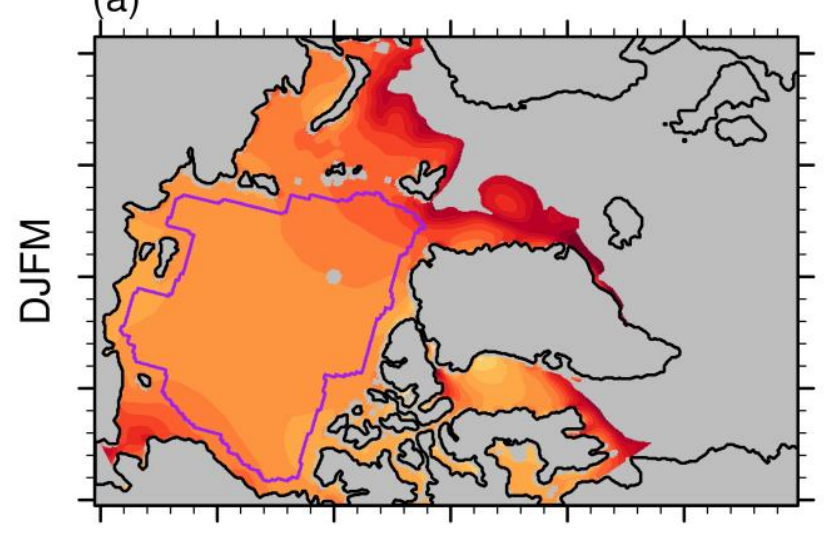

(c)

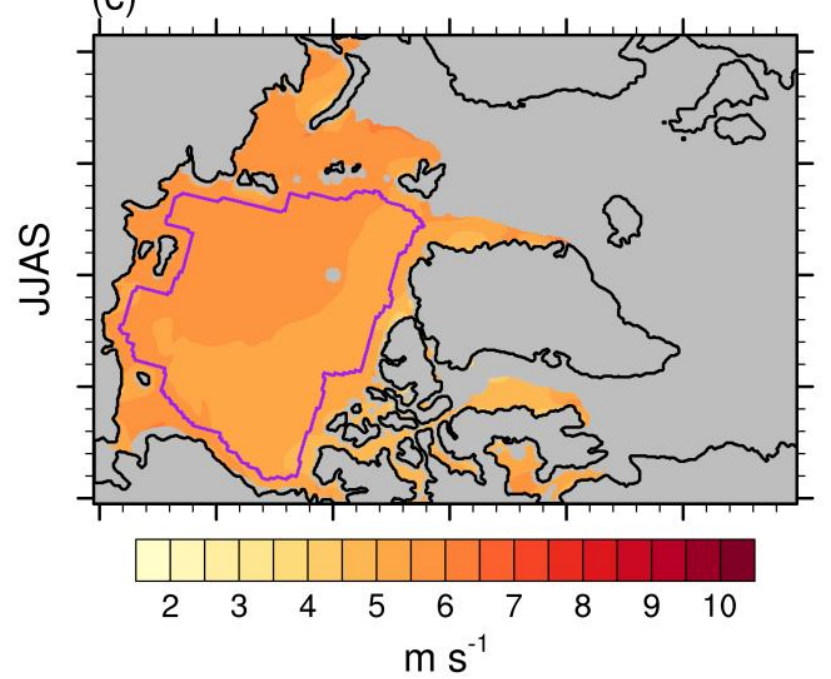

model - ERA-Interim

(b)

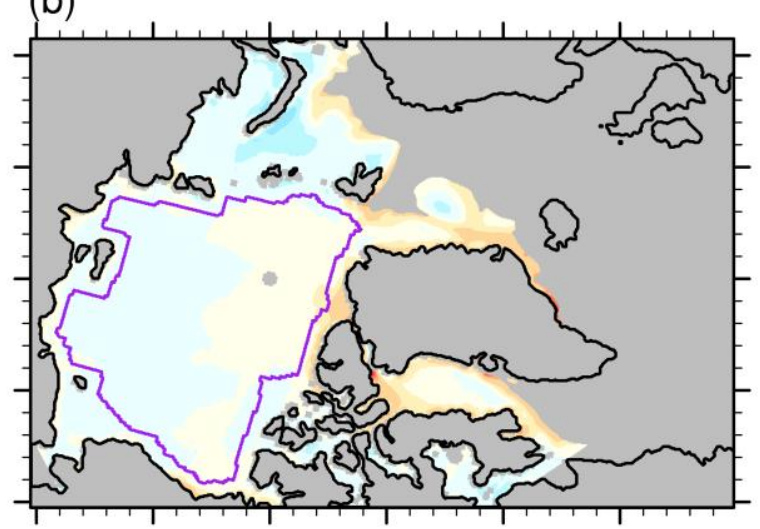

(d)

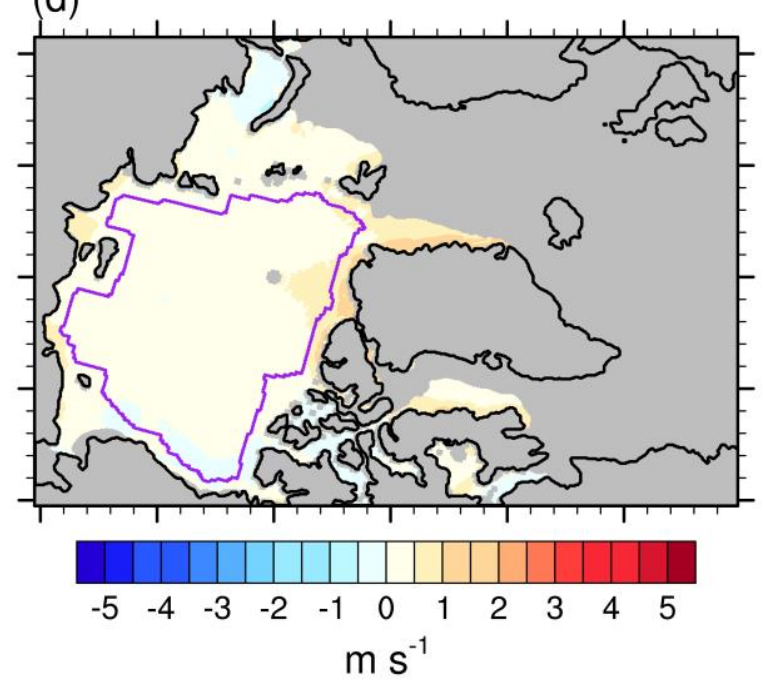

Figure S3: Mean spatial pattern of 10-m wind speed [ $\mathrm{m} \mathrm{s}^{-1}$ ] in the model (ensemble mean of HIRHAM-NAOSIM 2.0) for 2003-2014 (a) winter (DJFM) and (c) summer (JJAS). (b) and (d) are the model differences to the reanalysis ("Model - ERA-Interim") during winter and summer respectively. The purple line indicates the study domain used for the basin-wide analysis. 
DJFM

(a)

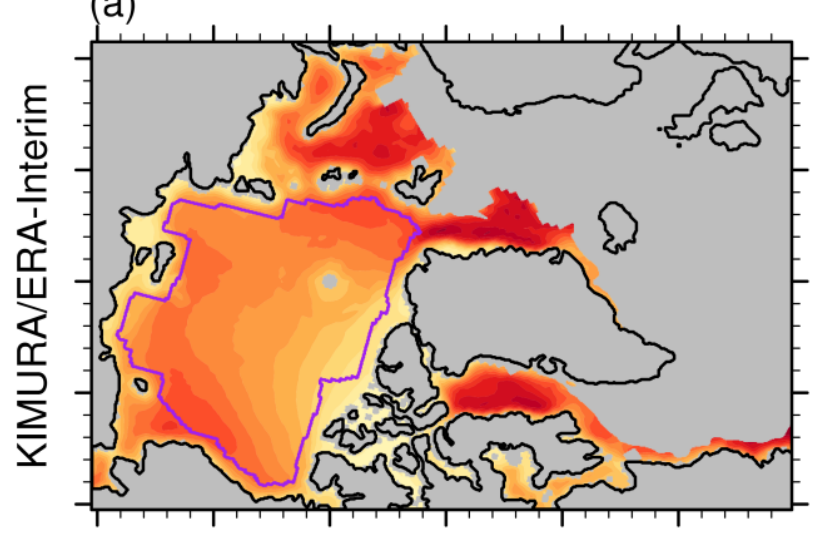

JJAS

(b)

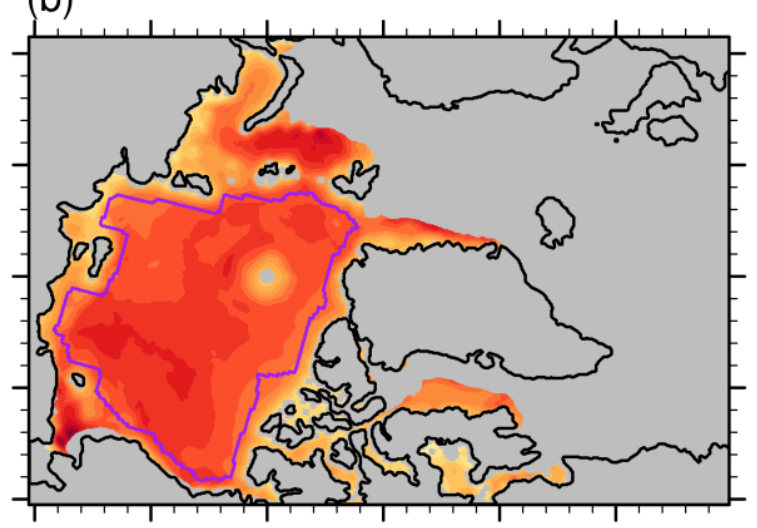

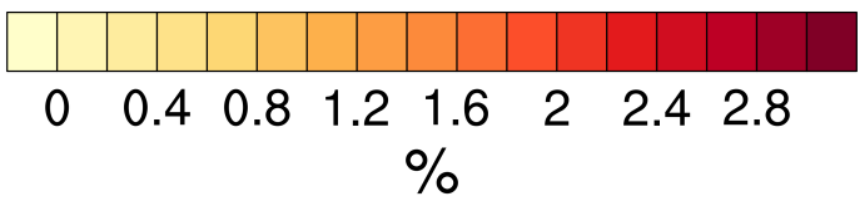

Figure S4: Mean spatial pattern of wind factor [\%] based on the observation/reanalysis ("KIMURA/ERA-I") for 2003-2014 (a) winter (DJFM) and (b) summer (JJAS). The purple line indicates the study domain used for the basin-wide analysis. 
(a)

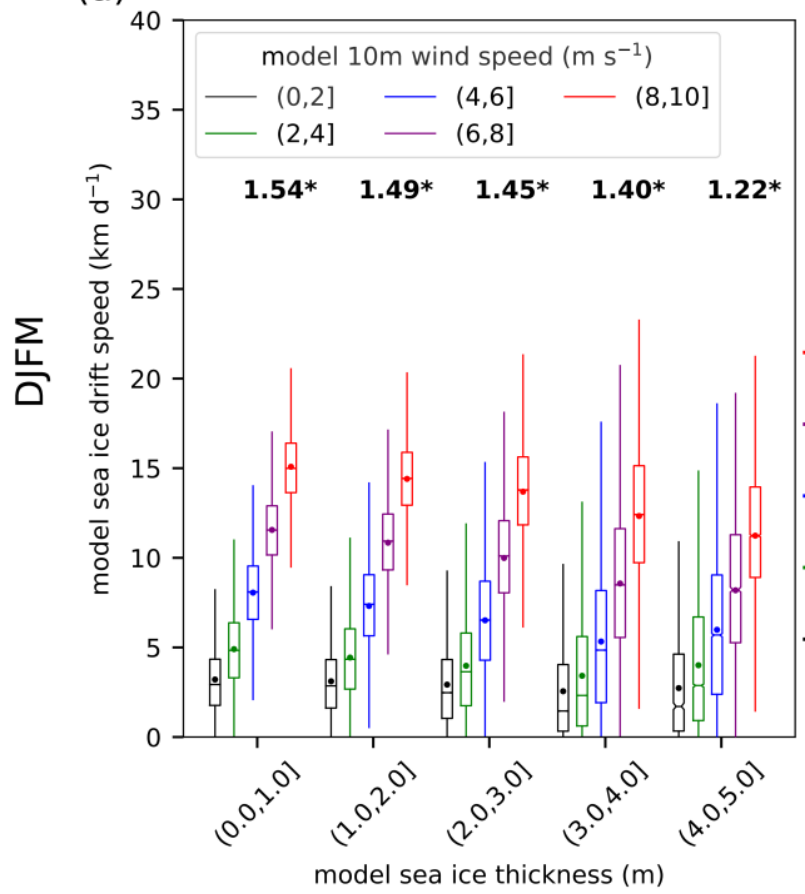

(c)

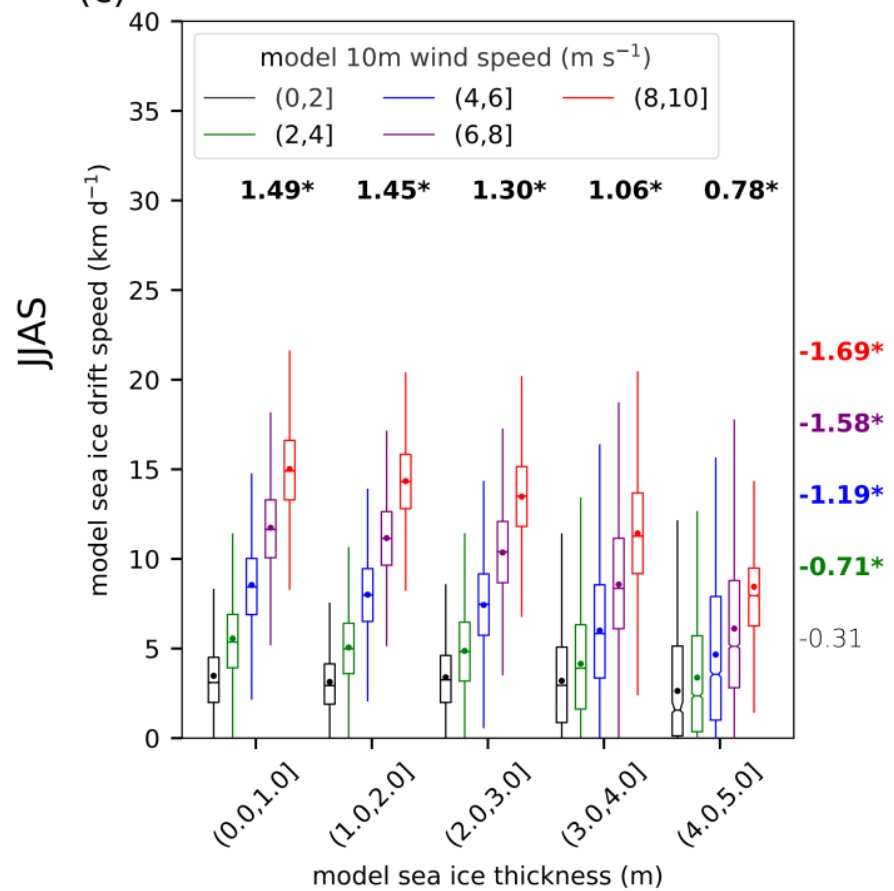

(b)

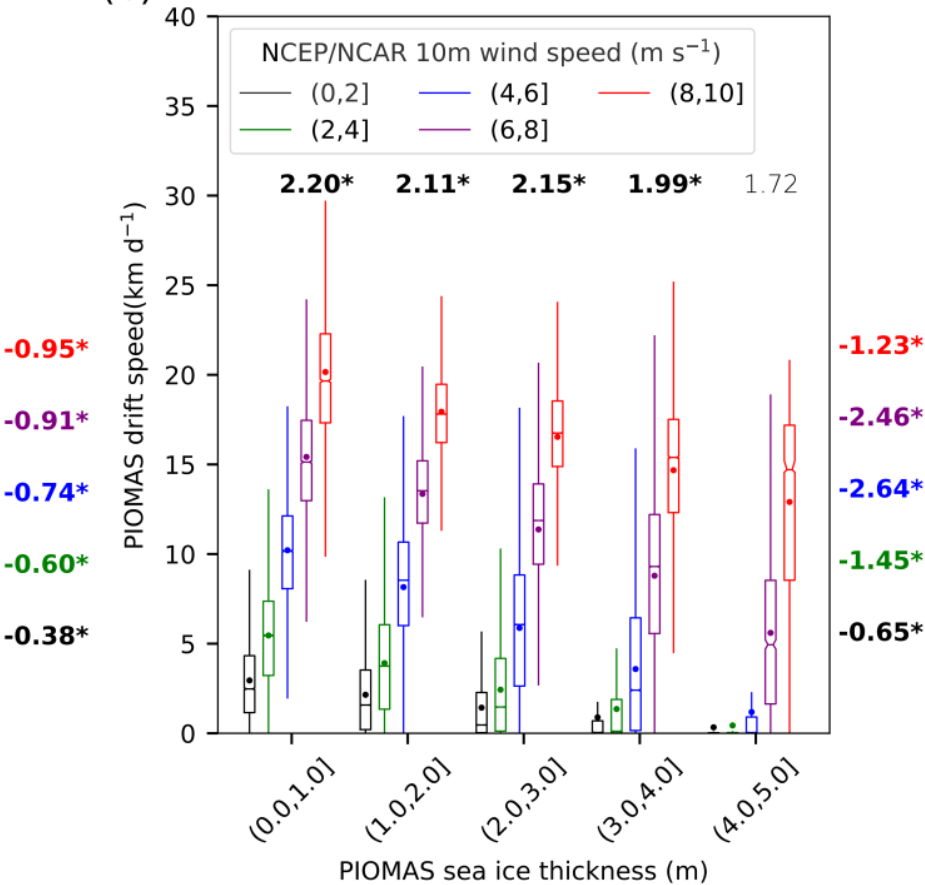

(d)

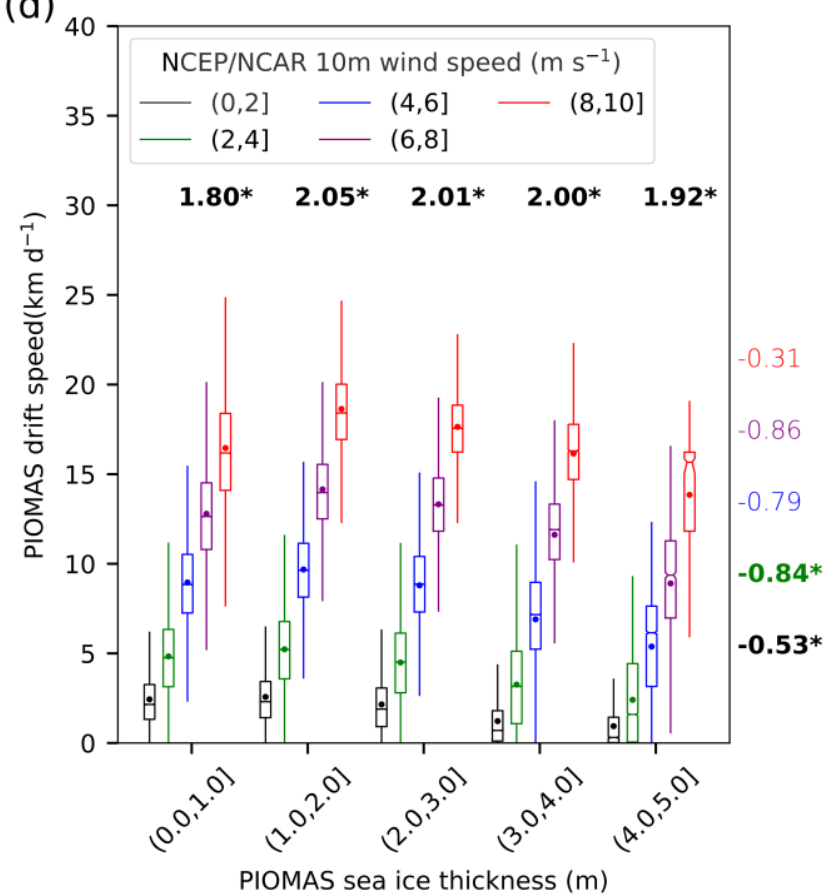

Figure S5: Box-whisker plots of the relationship between sea-ice drift speed and sea-ice thickness for different near-surface wind speed classes (different colors) for 2003-2014 (a) winter (DJFM) and (c) summer in the model (HIRHAM-NAOSIM 2.0). (b) and (d) are the same as that for (a) and (c) respectively, but based on PIOMAS data. For the model, all 10 ensemble members are included. The plot is based on daily data and on all grid points within the study domain indicated in Figure 1. The horizontal bar represents the median, the notch represents the $95 \%$ confidence interval of the median, the dot represents the mean, the top and bottom of the box represent the 75 th and 25 th percentiles, the upper/lower whiskers represent the maximum/minimum value within 1.5 times interquartile range (IQR) to $75 / 25$ percentiles. The numbers above the boxplots represent the slopes of sea-ice drift speed and near-surface wind fit lines (unit: km d ${ }^{-1}$ per $1 \mathrm{~m} \mathrm{~s}^{-1}$ wind speed change; font colors as for the wind speed classes). The numbers right of the boxplots represent the slopes of sea-ice thickness and sea-ice drift speed fit lines (unit: $\mathrm{km} \mathrm{d}^{-1}$ per $1 \mathrm{~m}$ sea-ice thickness change). A bold and asterisked number indicates that the slope of the fit line is significant at the $95 \%$ level. In the labels of different sea-ice thickness and 10-m wind speed classes, "(" means exclusive and "]" means inclusive. 